Produto \& Produção, vol. 9, n. 3, p. 47-53, out. 2008

\title{
Análise comparativa de três centros de desenvolvimento de produtos do setor automobilístico: a maturidade em gestão de projetos
}

\author{
Marly Monteiro de Carvalho, Dr. \\ Departamento de Engenharia de Produção, Escola Politécnica da USP, São Paulo/SP \\ marlymc@usp.br \\ André Segismundo, Mestrando \\ Departamento de Engenharia de Produção, Escola Politécnica da USP, São Paulo/SP \\ segismundo_andre@yahoo.com.br
}

\begin{abstract}
Em tempos de crescentes competição e globalização, o sucesso dos projetos se tornou ainda mais vital para a performance dos negócios, no entanto, estudos revelam que muitas empresas e setores ainda apresentam um nível básico em maturidade de gerenciamento de projetos. Neste cenário, o presente estudo pretende investigar a maturidade do gerenciamento de projetos no contexto do setor automobilístico. Foi feito um estudo exploratório em três diferentes unidades de negócio deste setor: Caminhões, Ônibus e Trem de Força. O assessment nível dois do PMMM foi aplicado à diretoria, média e baixa gerência de desenvolvimento de produtos de cada unidade, com um nível médio de resposta de 65\%. Como principais resultados, pode-se mencionar que as três unidades não atingiram a maturidade em gestão de projetos. Também se concluiu que não há diferença significativa entre as unidades Caminhões e Ônibus, as quais apresentaram vantagem com relação à unidade Trem de Força.
\end{abstract}

Palavras-chave: maturidade; gerenciamento de projetos; setor automobilístico

In time of increased competition and globalization, project success becomes even more critical to business performance, however studies have revealed that many companies and sectors still presents a basic level in project management maturity. At this scenario, the present research intends to investigate the project management maturity at the automotive sector context. An exploratory study was done at three different business units (BUs) of this sector: Trucks, Bus and Power Train. It was applied the assessment level two of PMMM for the directory and medium and low management levels of the development departments, with a response level of 65\%. As principal results, it is possible to mention that the three units have not yet reached the project management maturity. It was also concluded that there is no statistical relevant difference of the medium maturity level between the Trucks and Bus units, whose have shown advantage in comparison with the Power Train.

Key-words: maturity, project management, automotive sector

\section{Introdução}

Projeto, como uma atividade organizada da humanidade, pode provavelmente ser encontrado em diversas civilizações. Atualmente, toda construção, desenvolvimento de produtos e esforços em engenharia usam alguma estrutura formal de gerenciamento de projetos, tipicamente definidos como organizações temporárias para o atendimento de um objeto especifico (CLELAND; KING, 1983 apud SHENHAR, 2001) e, em tempos de competição e globalização crescentes, o sucesso dos projetos de uma organização se tornou ainda mais "chave" para a performance do negócio da mesma (SHENHAR et al., 2002).

Ainda assim, estudos revelam que muitas empresas e setores ainda apresentam um nível básico em maturidade de gerenciamento de projetos. Cooke-Davies e Arzymanow (2003) encontraram evidências de que o gerenciamento de projetos vem sendo desenvolvido há mais tempo em algumas indústrias em comparação com outras, além da influência cultural da própria organização, fatos que le- 
vam a uma significativa diferença de maturidade em gestão de projetos. Neste contexto, este trabalho busca estudar a maturidade de gerenciamento de projetos no setor automobilístico em diferentes centros de desenvolvimento de unidades de negócio brasileiras.

O artigo está estruturado em seis seções. As seções 2 e 3 apresentam os conceitos básicos de maturidade de gerenciamento de projetos. A seção 4 apresenta a abordagem metodológica utilizada, em que são apresentados os objetivos e as hipóteses, bem como os instrumentos de coleta de dados e as técnicas de análises utilizadas. A seção 5 apresenta o resultado do levantamento de campo, realizado em 3 três unidades de negócio: caminhões, ônibus e trem de força. Finalmente, a seção 6 traz as conclusões, limitações e recomendações para pesquisas futuras.

\section{Maturidade em gestão de projetos: conceitos}

Com relação ao conceito de maturidade, pode-se dizer que a mesma está associada a organizações cujos processos são capazes de produzir melhores outcomes (MCBRIDE et al., 2004). O conceito de maturidade de processos nasceu no movimento Total Quality Management (TQM), onde a aplicação de técnicas de controle estatístico de processo mostrou que o aprimoramento da maturidade de qualquer processo técnico leva a dois fatos: redução da variabilidade inerente ao processo e a um aprimoramento da performance média do mesmo. Através do muito utilizado Capability Maturity Model pelas indústrias de software, este conceito de maturidade de processo migrou para um mensurável processo de maturidade organizacional, evoluindo depois, para o conceito e modelo de maturidade em gestão de projetos (DAVIES; ARZYMANOW, 2003).

De acordo com Carvalho e Rabechini (2005), existem vários modelos de maturidade em gestão de projetos, sendo os mais difundidos: Capability Maturity Model (CMM) (HUMPHREY, 1989; PAULK et al., 1995), Project Management Maturity Model (PMMM) (KERZNER, 2000 e 2001) e o Organizational Project Management Maturity Model (OPM3) (PMI, 2003). A presente pesquisa baseouse no modelo PMMM (KERZNER, 2000 apud CARVALHO e RABECHINI, 2005), o qual propõe cinco níveis de desenvolvimento: nível 1 - linguagem comum; nível 2 processos comuns; nível 3 - metodologia singular; nível 4 - benchmarking; e nível 5 - melhoria contínua (CARVALHO et al., 2003).

Para Kerzner (2001), o nível 3 representa a maturidade, e os níveis 4 e 5 caracterizariam a excelência em gerenciamento de projetos. Carvalho e Rabechini Jr (2005) consideram o nível 2, como uma fase crítica e de transição entre a imaturidade (nível 1) e a maturidade (nível 3), pois é neste nível que existe o ciclo de vida em gerenciamento de projetos.

O ciclo de vida, identificado por Kerzner (2001) no nível 2 do PMMM, apresenta cinco fases, quais sejam: embrionária; reconhecimento da alta administração; reconhecimento da média gerência; crescimento e maturidade. As principais características da fase embrionária referem-se ao reconhecimento da importância do gerenciamento de projetos para a organização. Quando este reconhecimento atinge a alta administração, em geral caracterizado pela visibilidade em termos de suporte e o estabelecimento de um patrocinador no nível executivo, a segunda fase está caracterizada. Já na terceira fase, avalia-se o reconhecimento pela média gerência e de linha da relevância do gerenciamento de projetos. A fase de crescimento envolve o desenvolvimento de uma metodologia de gerenciamento de projetos pela organização e comprometimento com as atividades de planejamento.

A fase de maturidade resulta no desenvolvimento de um sistema de controle gerencial dos resultados do projeto e o desenvolvimento de um programa de formação em gestão de projetos. Embora caracterizado em fases, Carvalho e Rabechini Jr (2005) alertam que elas podem acontecer de forma simultânea e não necessariamente seqüenciais; como por exemplo, o reconhecimento da média gerência ser obtido antes que a alta gerência se sensibilize.

\section{Levantamentos empíricos sobre maturidade}

Alguns estudos empíricos sobre maturidade em gerenciamento de projetos estão disponíveis na literatura (GRANT; PENNYPACKER, 2006; COOKE-DAVIES; ARZYMANOW, 2003;ANDERSEN; JESSEN, 2003). Grant e Pennypacker (2006) desenvolveram um estudo em diferentes indústrias - serviços tecno-científicos, tecnologia da informação, financeira e seguros, e manufatureira - e concluem que o nível médio de maturidade para todas as indústrias foi dois, numa escala de cinco níveis possíveis, baseada no Capability Maturity Model (CMM). Grant e Pennypacker (2006) concluem ainda, que existe diferença significativa na maturidade das indústrias pesquisadas, em que a de serviços tecno-científicos se mostrou mais avançada, enquanto a manufatureira se mostrou a mais atrasada de todas. Andersen e Jessen (2003) também desenvolveram um estudo de campo com 59 gerentes de projeto, utilizando como estrutura o modelo OPM3 e seus construtos - projeto, programas e portfólio - e concluíram que há indícios de que a maturidade na base (gestão de projetos individuais) é maior do que no topo (gestão do portfólio). Além disto, os autores argumentam que a utilização de gestão de projetos é menor do que a ambição ou conhecimento sobre o tema. Finalmente, Cooke-Davies e 
Arzymanow (2003) fizeram um estudo em 31 organizações (9 organizações farmacêuticas de grande porte; 6 organizações farmacêuticas de médio porte; $\quad 5$ do setor de telecomunicação; 4 setor de defesa; 3 de serviços financeiros; 2 do setor de construção; 2 petroquímicas). Os autores compararam primeiramente as organizações do setor farmacêuticas de grande e médio porte, concluindo que nos quesitos grau de funcionamento de projeto, liderança e força de matriz, as organizações de médio porte apresentaram melhor desempenho com relação às de grande porte. Além disto, as organizações de indústrias de engenharia de bases tiveram pontuações mais altas do que os setores industriais que adotaram o gerenciamento de projeto mais recentemente, como serviços financeiros ou farmacêuticos. Considerando-se os resultados destes estudos quanto à maturidade em gerenciamento de projetos de diferentes indústrias, optou-se por estudar a questão de gerenciamento de projetos no setor automobilístico, com intuito de confrontar os resultados com este cenário internacional.

\section{Método de pesquisa}

A presente pesquisa possui como objetivo geral identificar o nível de maturidade em gestão de projetos no setor automobilístico. A opção metodológica usada foi a de estudo de múltiplos casos, cujos critérios de seleção foram além do setor, a importância da área de gestão de projetos de desenvolvimento de novos produtos. Para fazer um estudo longitudinal nestas organizações, optou-se pelo levantamento de dados documentais e entrevistar envolvidos em projetos recentes, destas organizações (YIN, 1981). A seleção de mais de uma unidade de análise foi adotada a fim de compará-las e obter indícios de lacunas na área de gestão de projetos e, ainda, gerar inferências que auxiliem no desenvolvimento de novas pesquisas relacionadas ao tema em questão no setor automobilístico nacional.

Como hipóteses, pressupõe-se que as unidades de negócio (ou Business Units, BUs) objeto de estudo se encontra no nível de conhecimento básico em gestão de projetos (nível dois, de acordo com o PMMM), além de apresentar diferenças significativas entre as mesmas.

Com base nestes critérios, foram selecionados 3 centros de desenvolvimento como unidades de análise: caminhões, ônibus e trem de força, cujo resultado do levantamento de campo será apresentado na seção 5 deste artigo.

Com base no referencial teórico, partiu-se da premissa que o nível de maturidade esperado para as organizações estudadas seria o dois do PMMM. Desta forma, optou-se por aplicar o questionário validado do ciclo de vida (life cycle assessment-level 2), sugerido para o nível 2.
No total foram enviados vinte e três questionários, para os diretores, média e baixa gerência das três unidades já citadas. Destes, foram devolvidos respondidos quinze, ou seja, obteve-se em média uma resposta de $65 \%$, sendo que a unidade de desenvolvimento de caminhões respondeu $100 \%$, ônibus $75 \%$ e trem de força, onde se obteve o menor número de respostas, $35 \%$.

A realização da análise comparativa da maturidade das três unidades de desenvolvimento de produto do setor automobilístico, bem como diferenças na percepção da maturidade por nível hierárquico, foram obtidas através de análise estatística das médias, conforme o teste estatístico T-Test. Partiu-se da hipótese nula de igualdade entre as médias, ou seja, mesmo nível de maturidade para as três unidades, e mesma percepção de maturidade para os três níveis hierárquicos analisados. Todas as tabelas, gráficos e testes estatísticos foram gerados através do software Microsoft Excel.

\section{Resultados e análises}

A análise da maturidade média das diferentes áreas de desenvolvimento de produtos das business units (BUs) Caminhões, Ônibus e Trem de Força, dentro das cinco fases do ciclo de vida do nível dois do PMMM pode ser visualizada através da Figura 01. Observa-se que as três BUs obtiveram uma pontuação razoável na fase embrionária, porém tal fato não se repete da mesma maneira uniforme para as demais fases, onde o distanciamento da BU Trem de Força em relação as demais se torna visível.

Realizando-se o T-Test, para um $P$-value de 0,05 , comprova-se estatisticamente com intervalo de confiança de $95 \%$ que as BUs Caminhões e Ônibus não apresentam maturidade média significativamente diferentes, enquanto que ao compará-las com a BU Trem de Força, a diferença é significativa - esta última se mostra bem mais imatura na média (veja Tabela 01). O fator que apresentou maior diferença entre as opiniões dos diretores foi a fase de maturidade, onde a área de Ônibus apresentou uma visão mais otimista, seguida por Caminhões e por fim, com grande diferença, Trem de Força.

Segundo o modelo do assessment nível dois do PMMM (KERZNER apudCARVALHO, M.M.; RABECHINI Jr, R., 2005), uma nota superior a seis pode evidenciar que a maturidade naquela fase foi atingida e, portanto, de acordo com a média da opinião dos executivos entrevistados, nenhuma das três BUs ainda atingiu por completo o nível de maturidade dois, o que leva a aprovação da hipótese um do estudo. 


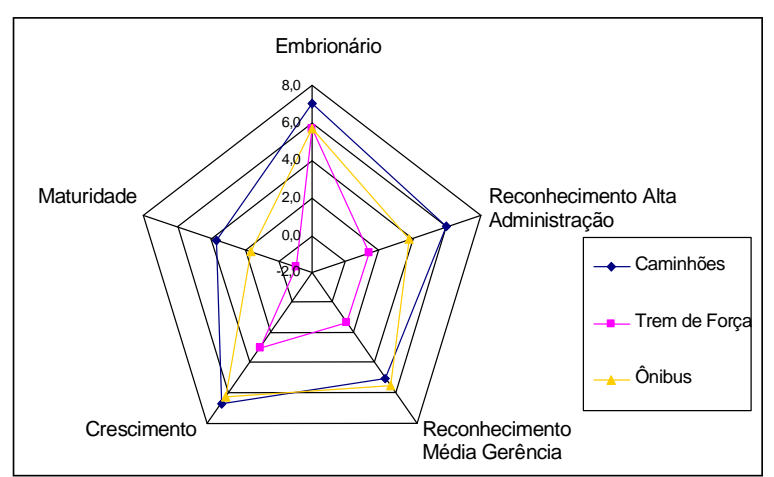

Figura 01 - Maturidade média das diferentes business units (BUs).

Tabela 01 - Análise cruzada da maturidade média das diferentes business units (BUs).

\begin{tabular}{|c|c|c|c|c|c|c|}
\hline & Embrionário & Rec. Alta Adm. & Rec.Méd. Ger. & Cres cimento & Maturidade & $\begin{array}{l}\text { Média } \\
\end{array}$ \\
\hline Caminhões & 7 & 5,9 & 5 & 6,7 & 3,7 & 5,7 \\
\hline Trem de Força & 5,7 & 1,3 & 1,3 & 3 & -1 & 2,1 \\
\hline Ônibus & 5,7 & 3,8 & 5,4 & 6,2 & 1,6 & 4,5 \\
\hline & F-test & T-test & & & & \\
\hline Caminhōes xT.Força & 0,2610 & 0,0042 & & & & \\
\hline Caminhões xônibus & 0,5350 & 0,0808 & & & & \\
\hline Ônibus xT.Força & 0,5985 & 0,0221 & & & & \\
\hline
\end{tabular}

A seguir analisou-se a maturidade das BUs na visão de cada um dos níveis hierárquicos entrevistados. A Figura 02 e a Tabela 02 exibem a opinião da diretoria de cada BU. Observa-se que a opinião dos diretores apresenta uma aderência razoável à maturidade média apresentada na Figura 01, pois Caminhões e Ônibus apresentam um perfil muito mais parecido, com médias de 4,2 e 5,4 respectivamente, que estatisticamente não são diferentes para um Pvalue de 0,05. A BU Trem de Força, no entanto, apresentou maturidade média na visão da sua diretoria de -0,4. Apesar destas diferenças, todos os diretores acreditam que suas BUs apresentam um crescimento, no mínimo, razoável ou bom.

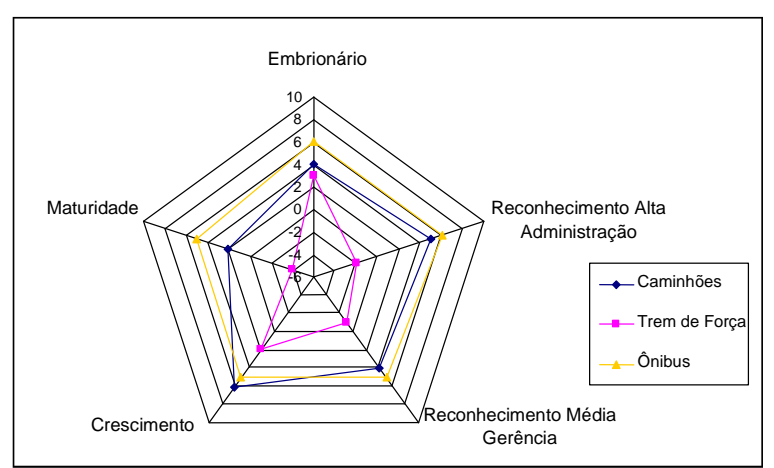

Figura 02 - Maturidade das diferentes business units (BUs) na visão da diretoria

Tabela 02 - Análise cruzada da maturidade das diferentes business units (BUs) na visão da diretoria

\begin{tabular}{|c|c|c|c|c|c|c|c|}
\hline & Embrionário & Rec. Alta Adm. & Rec. Méd. Ger. & Crescimento & Maturidade & $\mathrm{Me}$ & édia \\
\hline Caminhões & & 5 & 4 & 6 & & 2 & $\overline{4,2}$ \\
\hline Trem de Força & & -2 & -1 & 2 & & -4 & $-0,4$ \\
\hline \multirow[t]{2}{*}{ Ônibus } & & 6 & 5 & 5 & & 5 & 5,4 \\
\hline & F-test & $T$-test & & & & & \\
\hline Caminhỗes x T.Força & 0,226 & 0,0111 & & & & & \\
\hline Caminhōes $x$ Ônibus & 0,079 & 0,1447 & & & & & \\
\hline Ônibus x T.Forca & 0,007 & 0,0095 & & & & & \\
\hline
\end{tabular}

A visão da média gerência das BUs Caminhões e Trem de Força se mostraram bem mais otimistas que a opinião dos seus diretores (7,1 versus 4,2 e 5,0 versus -0,4, respectivamente), enquanto que na BU ônibus se verificou o contrário (3,6 versus 5,4$)$.

A Figura e a Tabela 03 mostram que, segundo seus gerentes, a BU Caminhões apresentou quatro das cinco fases com notas superiores a seis, exceto pela última fase de maturidade (nota 4,7). Todas as BUs apresentaram notas iguais ou maiores a seis na fase de crescimento, o que evidencia que seus gerentes acreditam estarem na direção certa quanto a maturidade em gerenciamento de projetos.

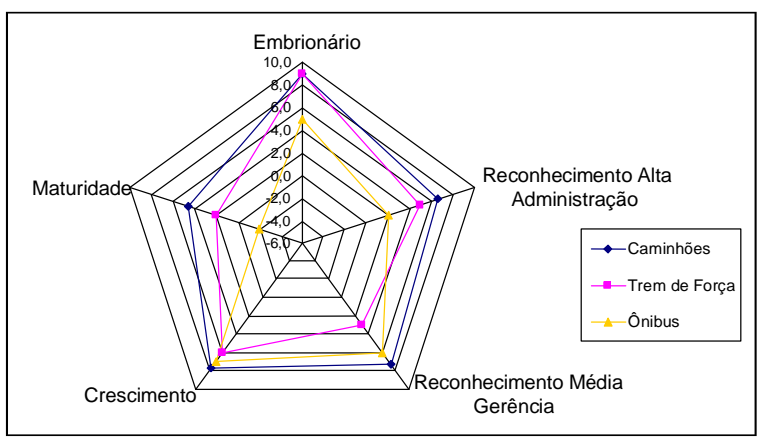

Figura 03 - Maturidade das diferentes business units (BUs) na visão da média gerência

Tabela 03 - Análise cruzada da maturidade das diferentes business units (BUs) na visão da média gerência

\begin{tabular}{|c|c|c|c|c|c|c|}
\hline & Embrionário & Rec. Alta Adm. & Rec. Méd. Ger. & Crescimento & Maturidade & Média \\
\hline Caminhões & 9 & 6,7 & 7,3 & 7,7 & 4,7 & 7,1 \\
\hline Trem de Força & 9 & 5 & 3 & 6 & 2 & 5,0 \\
\hline \multirow[t]{2}{*}{ Ônibus } & 5 & 2 & 6 & 7 & -2 & 3,6 \\
\hline & F-test & $\mathrm{T}$-test & & & & \\
\hline Caminhoôes x T.Força & 0,3095 & 0,0419 & & & & \\
\hline Caminhôes x Ônibus & 0,1328 & 0,0349 & & & & \\
\hline Ônibus x T.Força & 0,5926 & 0,3846 & & & & \\
\hline
\end{tabular}

Com relação à baixa gerência, pode-se concluir que a visão desta converge com a visão da diretoria, visto que as BUs Caminhões e Ônibus não apresentam diferença significativa estatisticamente para um P-Value de 0,05 , apresentando médias respectivas de 5,7 e 4,6. No entanto, conforme pode ser observado na Figura 04, a BU Trem de Força se mostra mais longe da sua maturidade também na opinião da sua baixa gerência (média 1,6), o que pode ser comprovado pelo T-Test apresentado na Tabela 04.

Um consenso parece existir na fase embrionária, onde todas as BUs obtiveram nota superior a 5 e, na fase de crescimento para as BUs Caminhões e ônibus, com notas 6,3 e 6,7 respectivamente. 


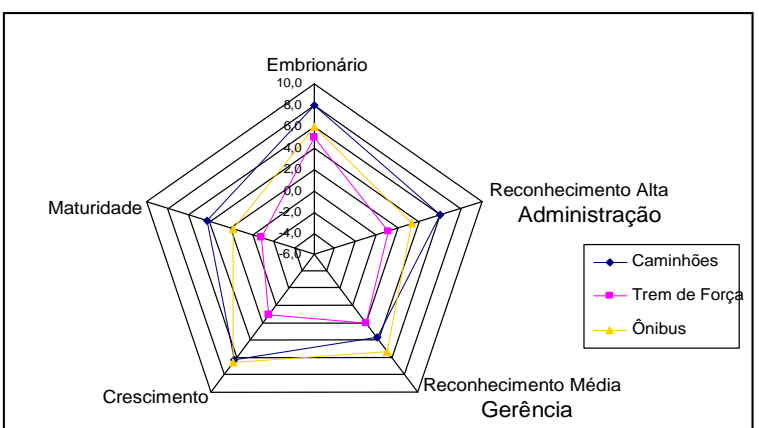

Figura 04 - Maturidade das diferentes business units (BUs) na visão da baixa gerência

Tabela 04 - Análise cruzada da maturidade das diferentes business units (BUs) na visão da baixa gerência

\begin{tabular}{|c|c|c|c|c|c|c|}
\hline & Embrionário & Rec. Alta Adm. & Rec. Méd. Ger. & Crescimento & Maturidade & Média \\
\hline Caminhões & 8 & 6 & 3,7 & 6,3 & 4,3 & 5,7 \\
\hline Trem de Força & 5 & 1 & 2 & 1 & -1 & 1,6 \\
\hline Ônibus & 6 & 3,3 & 5,3 & 6,7 & 1,7 & 4,6 \\
\hline & F-test & $T$-test & & & & \\
\hline Caminhōes x T.Força & 0,6426 & 0,0051 & & & & \\
\hline Caminhōes x Ônibus & 0,7273 & 0,2902 & & & & \\
\hline Ônibus x T.Força & 0,9072 & 0,0178 & & & & \\
\hline
\end{tabular}

A seguir, analisou-se a maturidade de cada BU cruzandose a opinião de cada nível hierárquico entrevistado. $\mathrm{Na}$ Figura e Tabela 05, pode-se observar os resultados para a BU Caminhões. Estatisticamente para um intervalo de confiança de 95\%, pode-se afirmar que a opinião da diretoria sobre a maturidade média difere da visão da média gerência (T-Test igual a 0,0093), principalmente quanto às fases embrionária, reconhecimento da média gerência e maturidade, sobre as quais a média gerência se mostrou mais otimista. A baixa gerência, no entanto, expressou opiniões mais similares à da diretoria, principalmente quanto ao reconhecimento do nível hierárquico intermediário. Em termos estatísticos, a baixa gerência por ter apresentado uma posição mais central, não apresentou diferenças significantes de suas médias com os outros dois níveis (Veja Tabela 05).

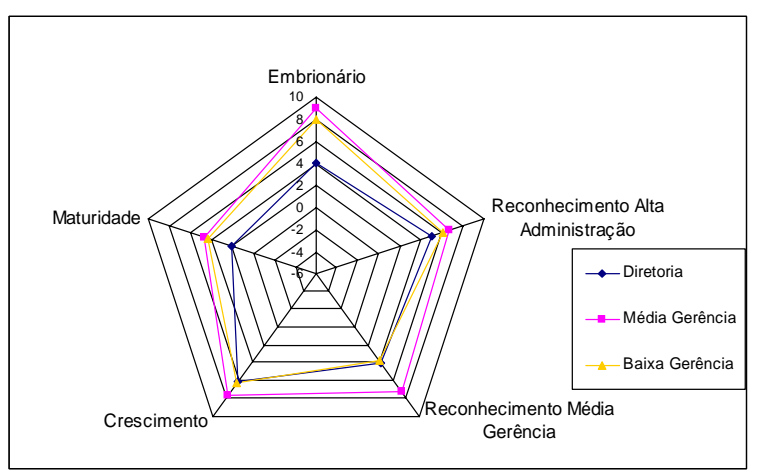

Figura 05 - Maturidade da BU Caminhões para os diferentes níveis hierárquicos
Com relação à BU Trem de Força, estatisticamente a média gerência diverge dos outros níveis hierárquicos, sendo esta bem mais otimista quanto à maturidade média de sua BU (Veja Tabela 06). Tanto a diretoria quanto a baixa gerência identificaram uma maturidade média da BU muito baixa, principalmente devido as fases de reconhecimento da alta e média administração, crescimento e maturidade, conforme mostra a Figura 06.

Tabela 05 - Análise cruzada da maturidade da BU Caminhões para os diferentes níveis hierárquicos.

\begin{tabular}{|c|c|c|c|c|c|c|}
\hline & Embrionário & Rec. Alta Adm. & Rec. Méd. Ger. & Crescimento & M aturidade & Média \\
\hline Diretoria & 4 & 5 & 4 & 6 & 2 & 4,2 \\
\hline Média Gerência & 9 & 6,7 & 7,3 & 7,7 & 4,7 & 7,1 \\
\hline \multirow[t]{3}{*}{ Baixa Gerência } & 8 & 6 & 3,7 & 6,3 & 4,3 & 5,7 \\
\hline & & & & & Média Geral & 5,6 \\
\hline & F-test & T -test & & & & \\
\hline Dir. x Méd. Ger. & 0,9098 & 0,0093 & & & & \\
\hline Dir. $x$ Baixa Ger. & 0,7897 & 0,1303 & & & & \\
\hline Méd. Ger. X Baixa Ger. & 0,8779 & 0,0673 & & & & \\
\hline
\end{tabular}

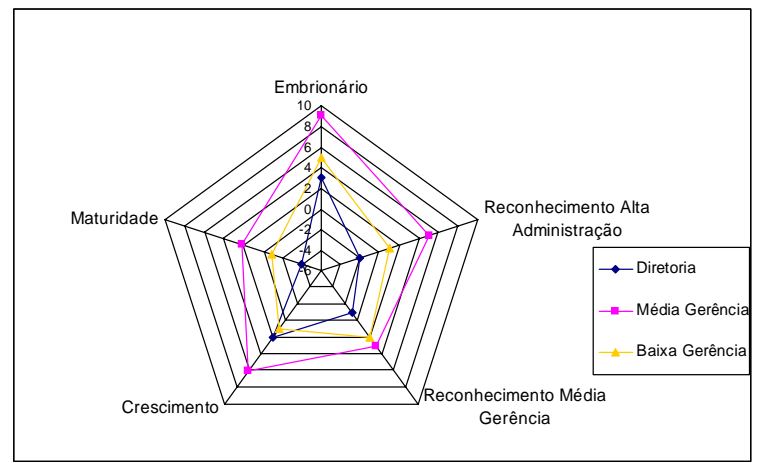

Figura 06 - Maturidade da BU Trem de Força para os diferentes níveis hierárquicos

Tabela 06 - Análise cruzada da maturidade da BU Trem de

\begin{tabular}{|c|c|c|c|c|c|c|}
\hline & Embrionário & Rec. Alta Adm. & Rec. Méd. Ger. & Crescimento & Maturidade & Média \\
\hline Diretoria & 3 & -2 & -1 & 2 & -4 & $-0,4$ \\
\hline Média Gerência & 9 & 5 & 3 & 6 & 2 & 5,0 \\
\hline \multirow[t]{3}{*}{ Baixa Gerência } & 5 & 1 & 2 & 1 & -1 & 1,6 \\
\hline & & & & & Média Geral & 2,1 \\
\hline & F-test & $T$-test & & & & \\
\hline Dir. x Méd. Ger. & 0,9241 & 0,0008 & & & & \\
\hline Dir. $x$ Baixa Ger. & 0,6088 & 0,0612 & & & & \\
\hline Méd. Ger. X Baixa Ger. & 0,6760 & 0,0074 & & & & \\
\hline
\end{tabular}

Força para os diferentes níveis hierárquicos.

Em relação a BU Ônibus, estatisticamente esta foi a única das três que não apresentou diferença significativa entre as opiniões de seus níveis hierárquicos entrevistados quanto ao seu nível de maturidade médio (Veja Figura e Tabela 07). Em termos de média geral apresentou maturidade de 4,5, nota não diferente pelo T-Test da BU Caminhões (média geral 5,6), fato que mostra que ainda não se atingiu por completo a maturidade do nível dois sugerida pelo PMMM. Apesar das médias não apresentarem diferença significativa, as fases de reconhecimento da alta administração e maturidade apresentaram divergências, onde para ambas a média gerência se mostrou menos otimista. 


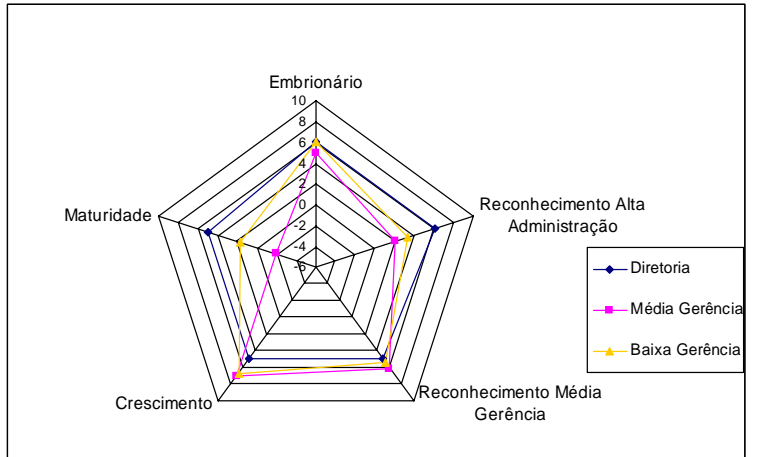

Figura 07 - Maturidade da BU Ônibus para os diferentes níveis hierárquicos

Tabela 07 - Análise cruzada da maturidade da BU Ônibus para os diferentes níveis hierárquicos.

\begin{tabular}{|c|c|c|c|c|c|c|}
\hline & Embrionária & Rec. Alta Adm. & Rec. Méd. Ger. & Crescimento & Maturidade & Média \\
\hline Diretoria & 6 & 6 & 5 & 5 & 5 & 5,4 \\
\hline Média Gerência & 5 & 2 & 6 & 7 & -2 & 3,6 \\
\hline \multirow[t]{3}{*}{ Baixa Gerência } & 6 & 3,3 & 5,3 & 6,7 & 1,7 & 4,6 \\
\hline & & & & & Média Geral & 4,5 \\
\hline & F-test & T-test & & & & \\
\hline Dir. x Méd. Ger. & 0,0029 & 0,3380 & & & & \\
\hline Dir. x Baixa Ger. & 0,0250 & 0,4461 & & & & \\
\hline Méd. Ger. X Baixa Ger. & 0,2941 & 0,2656 & & & & \\
\hline
\end{tabular}

\section{Considerações finais}

Dado o exposto, pode-se concluir que os centros de desenvolvimento das três BUs pesquisadas encontram-se ainda no nível dois de maturidade do modelo PMMM proposto por Kerzner (2001), fato que valida a hipótese proposta. A Hipótese ainda pressupunha que existiam diferenças significativas entre as BUs quanto a maturidade em gestão de projetos, porém neste sentido, a mesma foi confirmada apenas parcialmente, pois o estudo revelou que existe a diferença apenas ao se comparar a BU trem de Força com as demais. Foi comprovado que não existe diferença estatisticamente relevante apenas entre as BUs Caminhões e Ônibus, as quais se mostraram mais avançadas com relação ao tema estudado quando em comparação com a BU Trem de Força.

Como limitações do estudo, vale citar que o fato de o mesmo ter sido desenvolvido em uma única empresa automobilística, mesmo sendo esta de grande porte, não se pode utilizar (nem é o objetivo) suas conclusões para representar o setor. Além disso, apesar do nível de resposta médio ter sido alto (65\%), este não foi uniforme e, da BU Ônibus obteve-se no nível de média gerência apenas um retorno e, para Trem de Força, nível de gerencia média e baixa gerencia apenas um retorno. Tal fato compromete a representatividade das médias analisadas no item 06 do presente estudo.

Algumas conclusões pode-se ainda tirar de uma observação detalhada sobre o estudo, onde as três BUs apresen- tam tanto na média quanto na visão da maioria de seus executivos, boas notas na fase de crescimento, fato que pode levar a interpretação de que, apesar de não ter se alcançado ainda o nível dois de maturidade em sua plenitude, todas as BUs estão evoluindo a caminho do nível três. Ao se olhar cada BU separadamente, pode-se dizer que para Caminhões o apoio da alta administração quanto ao tema é reconhecido pelos níveis hierárquicos inferiores, contudo tanto a diretoria quanto a baixa administração atribuíram apenas notas intermediárias à média gerência. Na BU Trem de Força, as fases de reconhecimento da alta e média gerência foram muito pouco valorizados, e para Ônibus, a fase reconhecimento da alta administração apresentou notas da média e baixa gerencia, mais baixas do que da diretoria, o que talvez sugira que estes níveis não sentem o apoio necessário da diretoria para o tema gestão de projetos.

Como possíveis potenciais de melhoria em gestão de projetos para as BUs analisadas, sugere-se um investimento imediato em ações que se traduzam numa transparência mais efetiva do reconhecimento da alta e média administração, como por exemplo patrocinar e liberar os funcionários para palestras e cursos de gerenciamento de projetos, mostrar conhecimentos na gestão de projetos e disposição para inovação de processos, além de oferecer treinamento ou reciclagem para os executivos sobre gestão de projetos. Em médio prazo, para se atingir a maturidade, sugere-se ações como fortalecer o uso de métodos e ferramentas únicas e integradas para realização e controle de pacotes de trabalho, cronogramas, gestão de riscos, além do desenvolvimento sólido junto à estratégia de recursos humanos de um currículo em gestão de projetos e do tratamento da mesma como carreira na empresa.

Por fim, pode-se inferir que o presente estudo além de oferecer apenas uma simples contribuição para o avanço dos estudos no tema, pode servir de base para novas pesquisas mais abrangentes sobre maturidade em gestão de projetos para o setor automobilístico, ou ainda, agregando este último a uma pesquisa inter-setores como os de Grant e Pennypacker (2006) ou Davies e Arzymanow (2003).

\section{Referências}

ANDERSEN, E. S. \& JESSEN, S. A. Project maturity in organizations. International Journal of Project Management, v. 21, p. 457-461, 2003.

CARVALHO, M. M.; LAURINDO, F. J. B. \& PESSÔA, M. S. P. Information Technology Project management to achieve efficiency in Brazilian Companies. In: KAMEL, Sherif. (Org.). Managing Globally with Information Technology, Hershey, 2003, p. 260-271. 
CARVALHO, M.M.; RABECHINI Jr, R. Construindo Competências para Gerenciar Projetos: Teoria \& Casos. São Paulo: Editora Atlas, 2005. 317p.

COOKE-DAVIES, T.J.C.;ARZYMANOW,A. The maturity of project management in different industries: An investigation into variations between project management models. International Journal of Project Management, v.21, p.471-478, 2003.

GRANT, K.P.; PENNYPACKER, J.S. Project Management Maturity: an assessment of project management capabilities among and between selected industries. IEEE Transactions on Engineering Management, v.53, n.1, p.5968,2006.

KERZNER, H. Gestão de Projetos: as melhores práticas. Porto Alegre: Bookman, 2002.519p.

KERZNER, H. Strategic Planning for Project Management using a project management Maturity Model. Nova York, John Wiley \& Sons, 2001.

MCBRIDE, T.; HENDERSON-SELLERS, B. \& ZOWGHI, D. Project Management Capability Levels: an empirical study. In: 11TH ASIA-PACIFIC SOFTWARE ENGINEERINGCONFERENCE,p. 56-63, 2004.

PMI, Project Management Institute (2003). Organizational Project Management Maturity Model (OPM3). Project Management Institute Inc.

SHENHAR, A. J. \& RAZ, T.; DVIR, D. Risk management, project success, and technological uncertainty. $R \& D$ Management, v.32, n.2, p.101-109, 2002.

SHENHAR, A. J. One Size Does Not Fit All Projects: Exploring Classical Contingency Domains. Management Science, v.47, n.3, p.394-414, 2001. 